leothems with nearby planktic $\delta^{18} \mathrm{O}$ records may serve as a novel correlation tool.

Future strategies should include the initiation of new research networks to establish regionally integrated information on monsoon changes, such as tropical ice cores, and include East Pacific regions that are influenced by both monsoon and westerlies.

\section{C) Hemispheric and Interhemispheric Teleconnections}

Mark Maslin and Larry Peterson (Chairs) This group proposed five questions for testing:

1) Do tropical hydrology and ITCZ shifts respond consistently to changing highlatitude temperatures and meridional temperature gradients?

2) Do tropical warm-pool temperatures control the export of water vapor from low to higher latitudes, and what are the climatic feedbacks between these regions?

3) Are methane concentrations in ice cores indicative of methane release in tropical or high-latitude wetlands, and are they an important amplifier of hydrological changes?
4) ENSO as a potential forcing mechanism of past monsoonal intensity has only been recorded in varved sediments off Pakistan. Can a clear ENSO signal also be identified in proxy records from other monsoon regions?

5) High-latitude climate responds to enhanced dust transport due to changes in tropical wetness and aridity, yet what are the actual effects of high dust supply on climate?

\section{D) Human-scale events in the} Hydrological Cycle over the last $20 \mathrm{kyr}$

Ashish Sinha and David Anderson (Chairs) Group D focused on abrupt climate shifts and magnitudes of change that can be compared to historical records. Periods that appear particularly important include the last $2 \mathrm{kyr}$ and the $8.2 \mathrm{kyr}$ cooling event, implying that the following studies are required:

1) The extent to which climatic changes over the last $2 \mathrm{kyr}$-termed in Europe the "Little Ice Age", the Medieval and Roman Warm Periods-are connected to large-scale patterns of climate variability. Are these evident in worldwide anomalies of SST, droughts, and floods? To what extent are coeval variations in tropical monsoons connected to other tropical processes such as the Indonesian Throughflow, Walker, and Hadley circulations?

2) The role of tropical SST in driving hydrologic variability throughout the extratropics appears evident in model-based studies and instrumental records. Yet, long-term trends in this ocean-climate linkage are poorly known. New proxy records of the last $2 \mathrm{kyr}$ may help to assess the long-term influence of ocean SST patterns on hydrologic changes in remote regions.

This workshop demonstrated the merit of this relatively novel approach in addressing past variations in the hydrological cycle as a result of changes in ocean circulation. The presented results and subsequent discussions suggest that integration of paleoceanography and land paleoclimatology will yield dramatic progress in our understanding of the oceans' role in hydrologic change on many timescales.

\section{References}

Leduc, G., Vida, L., Tachikawa, K., Rostek, F., Sonzogni, C., Beaufort, L. and Bard, E., 2007: Moisture transport across Central America as a positive feedback on abrupt climatic changes, Nature, $\mathbf{4 4 5}$ as a positive

\title{
3rd Alexander von Humboldt International Conference: East Asian Monsoon, past, present and future
}

\section{Beijing, China, 9-11 August 2007}

\author{
André Berger ${ }^{1}$, Z. Ding ${ }^{2}$, Z. Guo ${ }^{2}$ and P. Fabian ${ }^{3}$ \\ 'Institute of Astronomy and Geophysics G. Lemaître, Catholic University of Louvain, Belgium; berger@astr.ucl.ac.be; \\ ${ }^{2}$ Institute of Geology and Geophysics, Chinese Academy of Sciences, Beijing, China; ${ }^{3}$ Technical University of Munich, Germany
}

The instrumental period of the meteorological record is too short to capture the full variability of the climate system and, in particular, to visualize the type of climate that is predicted to occur over the next decades and centuries. It is therefore, important to reconstruct past climates and understand past climatic variations. Marine deep-sea cores and ice cores have and will continue to contribute to our understanding. Land records also contribute significantly, particularly at the regional scale.

The Third European Geosciences Union (EGU) Alexander von Humboldt International Conference was devoted to the "East Asian Monsoon, Past, Present and Future". Both records of the past and present-day observations and model experiments were reviewed, to better understand the mechanisms driving its behavior and to allow for better predictions of it and its impacts.
60 oral presentations and 26 posters gave an excellent overview of the EAM and its evolution over the last $25 \mathrm{Myr}$, gathering important records and modeling results. The abstracts of the papers and posters are available in "Program in details" at www. conferencenet.org/conference/3rdAVH/ $\mathrm{html} /$ whatnew.htm, among them some scientific results to illustrate the EAM behavior at the different timescales covered during the meeting.

J. Guiot presented information on the mechanistic vegetation models that clarify the minimum climatic changes required to produce the vegetation shifts observed in paleodata.

The impact of the uplift of the Tibetan Plateau (TP) and the Rockies (RC) on Asian summer and winter monsoon climate was investigated, using both data and models for the last tens of million of years. Using the Meteorological Research Institue-coupled general circulation model, T. Yasunari

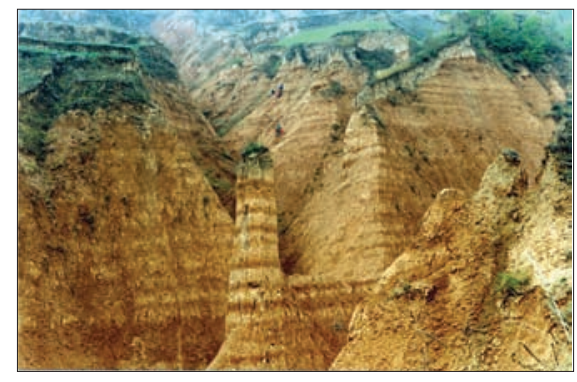

Figure 1: Field photo showing the alternation of loess (yellow layers) and paleosols (red-brown layers) in Miocene loess-soil sequences from the Chinese Loess Plateau, Gansu Province (courtesy of Zhengtang Guo, IGGCAS Beijing).

showed that, the zonal asymmetry of SSTs in the subtropical North Pacific is emphasized by the presence of both TP and RC, and enhancement of the Asian summer monsoon climate is likely to appear as an overall effect of the atmosphere-ocean interactions principally in the Pacific but also secondarily in the North Atlantic.

Z. Guo and Z. An both showed that the climate pattern in Asia experienced 
major reorganization near the Miocene/ Oligocene boundary that was characterized by the onset of a monsoon-dominated regime, replacing the zonal one that dominated during the Paleogene. Since then, eolian dust continues to be deposited in northern China, due to the formation of inland deserts as dust sources and the winter monsoon as a dust carrier, whereas paleosols interbedded in the eolian sequences are indicative of a strong summer monsoon. There were several pulses of TP growth northeastward between 1.3 and 1.0 Myr BP and after 0.6 Myr BP, which were responsible for the stepwise significant intensification of summer monsoons and the aridification of inland Asia.

S. Clemens discussed the phase evolution of Indo-Asian monsoons and global ice volume, suggesting that it requires changes to the marine oxygen isotopic chronostratigraphy (Marine Isotope Stages; MIS) prior to 3 Myr BP to achieve internally consistent and physically plausible responses among summer and winter monsoon circulation, changes in global ice volume, and orbital forcing.

Q. Yin (et al.) demonstrated from modeling experiments that although deep sea and ice core records show a cool MIS 13 interglacial with low greenhouse gas concentrations, the astronomical and ice sheet forcings at $\sim 500$ kyr BP are mainly responsible for the exceptionally intense East Asian Summer Monsoon (EASM), in agreement with the proxy record.

A series of papers were also devoted to the climatic optimum of the Holocene. Using a coupled ocean-atmosphere general circulation model, R. Ohgaito and A. AbeOuchi found that ocean thermodynamics plays an important role in mitigating the African/Asian monsoon enhancements, whereas ocean dynamics have minor effects. Y. Zhao and S.P. Harrison also discussed oceanic influence on the monsoon $6 \mathrm{kyr} \mathrm{BP}$ and showed that ocean feedbacks amplify the astronomically induced increase in eastern Asian monsoon precipitation, but dampen it in northern India. Additionally, C. Marzin and P. Braconnot explained the differences in the behavior of the different monsoon regions throughout the Holocene, through the large scale astronomical heating gradients, the role of the Tibetan Plateau snow cover and teleconnections between the Asian and African monsoon.

Among the papers dealing with the last hundreds of years, T. Yao used the Tibetan ice core record to show that the Tibetan Plateau was warmer during the $20^{\text {th }}$ century than any time during the past 1 kyr, but that the temperature changes on
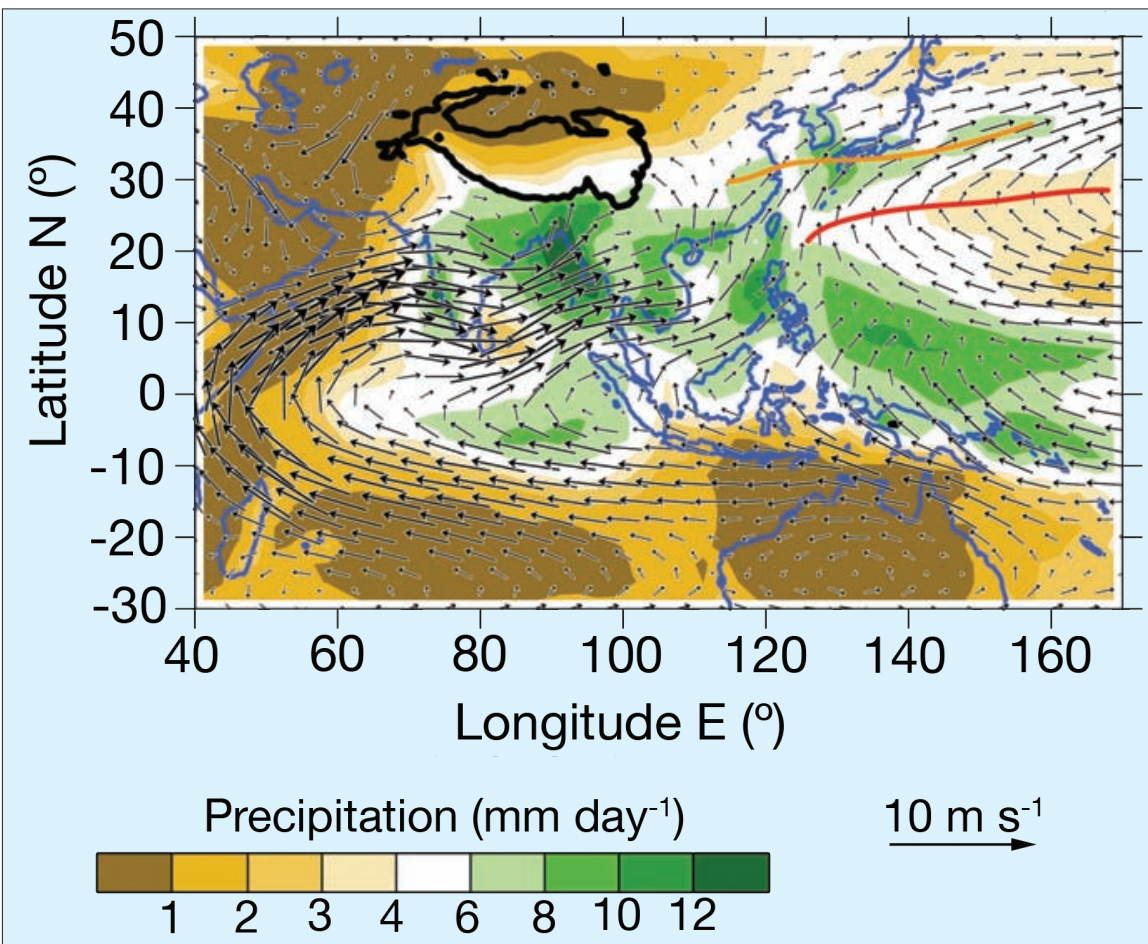

Figure 2: Asian summer (June-July-August) monsoon precipitation and wind field (Courtesy of Bin Wang, University of Hawaii). Black line represents $3000 \mathrm{~m}$ topographic contour, which outlines the Tibetan Plateau. Red and orange lines represent the subtropical rain band and the ridge of the subtropical high, respectively.

its northern and southern sides were different, reflecting the influence of the Asian monsoon over that period.

Finally, a few papers dealt with the prediction of climate and East Asian monsoon during the next century. From an ensemble of coupled ocean-atmosphere models used in IPCC, R.H. Kripalani suggested an average increase in precipitation of $8 \%$ over the East Asian region.

Analysis of present-day dynamics of the EASM suggests that the mechanisms operating on the annual and interannual timescales are determined, respectively, by external forcing (orbital forcing and land-sea configuration) and internal feedback processes, such as (remote) El Niño/ La Niña and monsoon-ocean-land interaction (Bin Wang). The coupling between the East Asia and Australian monsoon is more robust than that between the Indian monsoon and Australian monsoon, at both annual and interannual timescales. The interannual variability of the EASM is primarily attributed to ENSO and local atmosphere-ocean interaction. These conclusions have implications for EAM variability on orbital timescales. While on orbital timescales EASM variability may be attributed primarily to variations in orbital forcing, drastic changes in the Pacific thermal condition may also considerably alter the East Asian-Australian monsoon intensity. An important question is how the EASM variation on orbital timescales is linked to the variation of the Intertropical Convergence Zone (ITCZ). A prevailing notion in the paleoclimate community is that the northward movement of ITCZ would cause an enhanced EASM, while the present-day monsoon dynamics suggest the opposite.

As a side event of the conference, the new PAGES working group "Global Monsoon" was launched with a townhall meeting. The concept and present-day perspective of the global monsoon, and the goals and methods of implementation were discussed. It was concluded that a global view of the monsoon would aid in understanding the behavior of the regional monsoon systems.

This conference was a great promotion of international collaboration on the EAM between China and the communities of scientists related to EGU and PAGES. The invited lectures presented a very successful overview of monsoon studies. Due to our efforts, we expect that meteorologists dealing with present-day monsoon will become more deeply involved in future discussions and reviews. Our meeting was the first step towards cross-disciplinary exchanges in China and international exchanges on monsoon and its impacts on society. It also helped to promote EGU and its journal "Climate of the Past".

\section{Acknowledgements}

We thank the sponsors for their support: EGU, Chinese Academy of Sciences (CAS), PAGES, Foreign Affairs Bureau of CAS, and the Institute of Geology and Geophysics of CAS 